\title{
Structure and Characterization of Vertically Aligned Single-Walled Carbon Nanotube Bundles
}

\author{
Francisco Márquez, ${ }^{1,2}$ Vicente López, ${ }^{3}$ Carmen Morant, ${ }^{1}$ \\ Rolando Roque-Malherbe, ${ }^{2}$ Concepción Domingo, ${ }^{4}$ Eduardo Elizalde, ${ }^{1}$ and Félix Zamora ${ }^{3}$ \\ ${ }^{1}$ Departamento de Física Aplicada C-XII, Universidad Autónoma de Madrid, Cantoblanco, 28049 Madrid, Spain \\ ${ }^{2}$ Institute for Physical Chemical Applied Research IPCAR, School of Science and Technology, University of Turabo Gurabo PR, \\ 00778, USA \\ ${ }^{3}$ Departamento de Química Inorgánica C-VIII, Universidad Autónoma de Madrid, Cantoblanco, 28049 Madrid, Spain \\ ${ }^{4}$ Instituto de Estructura de la Materia, CSIC, Serrano 123, 28006 Madrid, Spain \\ Correspondence should be addressed to Francisco Márquez, fmarquez@suagm.edu
}

Received 9 August 2010; Accepted 2 September 2010

Academic Editor: Donglu Shi

Copyright () 2010 Francisco Márquez et al. This is an open access article distributed under the Creative Commons Attribution License, which permits unrestricted use, distribution, and reproduction in any medium, provided the original work is properly cited.

Arrays of vertically aligned single-walled carbon nanotube bundles, SWCNTs, have been synthesized by simple alcohol catalytic chemical vapor deposition process, carried out at $800^{\circ} \mathrm{C}$. The formed SWCNTs are organized in small groups perpendicularly aligned and attached to the substrate. These small bundles show a constant diameter of $c a .30 \mathrm{~nm}$ and are formed by the adhesion of no more than twenty individual SWCNTs perfectly aligned along their length.

\section{Introduction}

Since the landmark paper on carbon nanotubes (CNTs) in 1991 by Iijima $[1,2]$, there have been relevant research efforts on this new material. This great interest has been due to their unique mechanical [3], electronic $[4,5]$, and chemical properties [6] and their potential applications as field emitters [7-9], development of new composites, and conductive coatings [10], in energy storage [11], thermal materials [12], catalyst supports [13], and many other applications in nanometer scale engineering. However, the growth of aligned CNTs is paramount, for many of these applications are fully exploited. That is the reason why during the last few years many research groups have been focused on the design of new methods for controlling the CNT morphology [14-16]. In fact until a few years ago, alignment of single-walled carbon nanotubes (SWCNTs) was achieved by using strong electromagnetic fields [17-19]. Hata et al. described the attractive synthesis of highly aligned SWCNTs of millimetric dimensions by chemical vapor deposition (CVD) in presence of water vapor [20]. At present, two different fabrication methods for obtaining vertically aligned CNTs are used: (i) the direct growth by thermal catalytic chemical vapor deposition (CCVD) [21] and (ii) the screen printing technology from a paste mixture of CNTs [22]. Nevertheless, these approaches have clear limitations, and, in the case of the screen-printing process, the use of organic additives is a serious problem for their application in optoelectronic technology.

One of the most promising alternative procedures for obtaining aligned SWCNTs is that reported by Maruyama et al. [23-25], in which a mixture of $\mathrm{Co}^{\mathrm{II}}$ and $\mathrm{Mo}^{\mathrm{II}}$ salts is used as catalyst precursor and the growth is achieved by CVD using alcohol as carbon source. In this case, even though the uniformity and homogeneity achieved by this procedure have been sufficiently proven, the vertical alignment of SWCNTs is partially obtained when CNTs are high enough.

In this paper we report a method for the synthesis of vertically aligned SWCNTs, with high linearity and high density, based on the CCVD on silicon and quartz surfaces. Surprisingly the obtained SWCNTs are grouped in small bundles of $c a$. 20 SWCNTs. 


\section{Experimental Section}

2.1. Preparation of Supported Catalysts. The preparation procedure for supporting the catalyst precursor has been described elsewhere [25]. In this method Co-Mo acetate solutions are deposited on the substrates by dip coating following the next procedure: $\mathrm{Co}\left(\mathrm{CH}_{3} \mathrm{COO}\right)_{2} \cdot 4 \mathrm{H}_{2} \mathrm{O}$ and $\mathrm{Mo}\left(\mathrm{CH}_{3} \mathrm{COO}\right)_{2}$ diluted solutions in absolute ethanol was used as catalyst sources. Typically for preparing $100 \mathrm{~mL}$ of the corresponding acetate solution $0.02 \mathrm{~g}$ of the $\mathrm{Mo}^{\mathrm{II}}$ salt or $0.04 \mathrm{~g}$ of the $\mathrm{Co}^{\mathrm{II}}$ salt were used. Both solutions were sonicated for $30 \mathrm{~min}$ and stirred for $2 \mathrm{~h}$. Acetate solutions were kept in the dark to prevent photodecomposition. Silicon wafers (100) from El-CAT Inc. and fused quartz with both sides optically polished from SPI Supplies (quartz slide $25.4 \times 76 \mathrm{~mm}$ super smooth) were used as substrates. Substrates were cleaned with isopropyl alcohol and next dried in an oven at $70^{\circ} \mathrm{C}$ before use. The dip-coating was made in two steps in which the substrates are immersed into the acetate solutions and maintained there about $10 \mathrm{sec}$. In first step the substrates are immersed into the $\mathrm{Mo}^{\mathrm{II}}$ acetate solution and subsequently calcined in an oven in air at about $673 \mathrm{~K}$ for $20 \mathrm{~min}$. After that the substrates are cooled to room temperature and the dip-coating process is repeated by using the $\mathrm{Co}^{\mathrm{II}}$ acetate solution. Next, the substrates are calcined again in an oven at $673 \mathrm{~K}$ for $20 \mathrm{~min}$. As a result, organics are removed from the surfaces and the metals are oxidized. In the case of Mo, this metal forms an oxide layer that is expected to prevent the aggregation of the metallic Co particles formed during the CVD treatment that are the responsible for the growth of SWCNTs.

2.2. CVD Growth of SWCNTs. We have used a homemade thermal CVD system, composed by a three-entry system (Figure 1). A cylindrical quartz reactor with an inner diameter of $25 \mathrm{~mm}$ and a length of $1 \mathrm{~m}$ was installed inside a tubular furnace. Substrates in a ceramic boat were introduced within the quartz reactor. Next, the system was closed and evacuated to $10^{-2} \mathrm{~Pa}$, by using a mechanical pump. After $15 \mathrm{~min}$ the mechanical pump was stopped and a mixture of $90 \% \mathrm{~N}_{2}$ and $10 \% \mathrm{H}_{2}$ gas was incorporated into the reactor (flow rate of $300 \mathrm{sccm}$ ). Simultaneously, the reactor was heated up to $1073 \mathrm{~K}\left(10 \mathrm{~K} \cdot \mathrm{min}^{-1}\right)$. Once reaching the synthesis temperature, the $\mathrm{N}_{2}-\mathrm{H}_{2}$ flow was stopped and a mixture of $10 \% \mathrm{H}_{2}$ and $90 \% \mathrm{~N}_{2}$ with ethanol $(99.5 \%)$ vaporized into the nitrogen stream was introduced into the chamber at a flow rate of $200 \mathrm{sccm}$. The growth time was typically $5 \mathrm{~min}$ and apparently no changes were observed for longer times. The growth was typically terminated by switching the gas to $\mathrm{N}_{2}(300 \mathrm{sccm})$ and cooling down the furnace.

2.3. Characterization Methods. Field emission scanning electron microscopy (FESEM, JEOL JM6400) and highresolution transmission electron microscopy (HRTEM, JEOL JEM-3000F) were used to study the morphology, alignment, and main characteristics of the as-synthesized and purified CNTs. Raman spectra were also recorded using a Confocal Raman Microscope (Renishaw RM2000) equipped with laser sources at $514 \mathrm{~nm}, 633 \mathrm{~nm}$, and $785 \mathrm{~nm}$, a Leica microscope, and an electrically refrigerated CCD camera. The spectral resolution was set at $4 \mathrm{~cm}^{-1}$, laser power employed was less than $10 \mathrm{~mW}$, and acquisition time of each spectrum was around $50 \mathrm{sec}$.

HRTEM samples were prepared by dispersing the synthesized SWCNTs in ethanol followed by homogenization and then placing $5 \mu \mathrm{L}$ of this solution onto a copper grid coated with a lacy carbon film.

The synthesized SWCNTs were studied with the help of a TQ500 Thermogravimetric Analyzer (TGA). The sample was thermostatized at $23^{\circ} \mathrm{C}$, in a flow of nitrogen $(100 \mathrm{~mL} / \mathrm{min})$, and after that the temperature was linearly scanned, at a heating rate of $10^{\circ} \mathrm{C} / \mathrm{min}$, up to $800^{\circ} \mathrm{C}$. The data collection, the temperature control, the programmed heating rate, and the gas switching were electronically controlled by the instrument. The TGA data were collected as $M_{t}$ (wt.\%) versus $T\left({ }^{\circ} \mathrm{C}\right)$ profile, where $M_{t}$ is the loss of mass. The gas used in the TGA characterization was pure $N_{2}(99.9999 \%$ purity).

The specific surface area of the as-synthesized SWCNTs was determined by using the BET method [26-29]. The determination of the micropore volume was carried out with the Dubinin plot method [30] and the Langmuirtype isotherm equation for micropore volume filling plot methodology [29, 31]. The Saito-Foley Method was used for determining the micropore size distribution [32-34], and the Non local Density-Functional Method for determining the whole pore size distribution $[29,35]$. These methodologies were applied to experimental nitrogen adsorption isotherms at $77 \mathrm{~K}$, obtained for the SWCNTs using an Accelerated Surface Area and Porosimetry System, Autosorb-1, provided by Quantachrome Instruments. The equipment was previously calibrated with a zeolite A provided by Quantachrome Instruments as a standard.

\section{Results and Discussion}

The method used to produce the CNTs is based on that previously published by Murakami et al. [25] however, our approach simplifies the synthetic conditions previously required since in the procedure vacuum the quartz tube reactor was not used and the control of the gas mixture pressure during the process was unnecessary (Figure 1).

Figure 2 shows the field emission scanning electron microscopy (FESEM) image of the "as grown" SWCNTs from ethanol as carbon source at $1073 \mathrm{~K}$ on quartz substrates. As can be seen there, CNTs are vertically aligned on the substrate surfaces. The CNTs show a very high density and an averaged diameter of $c a .30 \mathrm{~nm}$. The length of the nanotubes is of ca. $5 \mu \mathrm{m}$ for $5 \mathrm{~min}$ of growth even though previous results confirm that it depends on the synthesis procedure (flow of $\mathrm{N}_{2}$-ethanol, temperature, and catalyst). High-resolution transmission electron microscopy, HRTEM, revealed exclusively the presence of small packets of SWCNTs without any double-walled or multiwalled carbon nanotubes. These SWCNTs were grown longitudinally aligned, showing a homogeneous diameter of $c a .1 .2 \mathrm{~nm}$ (see the magnification of Figure 3(a)). These bundles of SWCNT are formed by 
TABLE 1: Measured adsorption parameters.

\begin{tabular}{lccccc}
\hline Sample & $S^{\mathrm{BET}}\left[\mathrm{m}^{2} / \mathrm{g}\right]$ & $W_{\mathrm{MP}}^{\mathrm{Dubinin}}\left[\mathrm{cm}^{3} / \mathrm{g}\right]$ & $W_{\mathrm{MP}}^{\mathrm{LT}}\left[\mathrm{cm}^{3} / \mathrm{g}\right]$ & $D_{\text {mode }}^{\mathrm{SF}}[\mathrm{nm}]$ & $D_{\text {mode }}^{\mathrm{NLDFT}}[\mathrm{nm}]$ \\
\hline SWCNTs (as-synthesized) & 530 & 0.22 & 0.20 & 1.3 & 1.4 \\
\hline
\end{tabular}

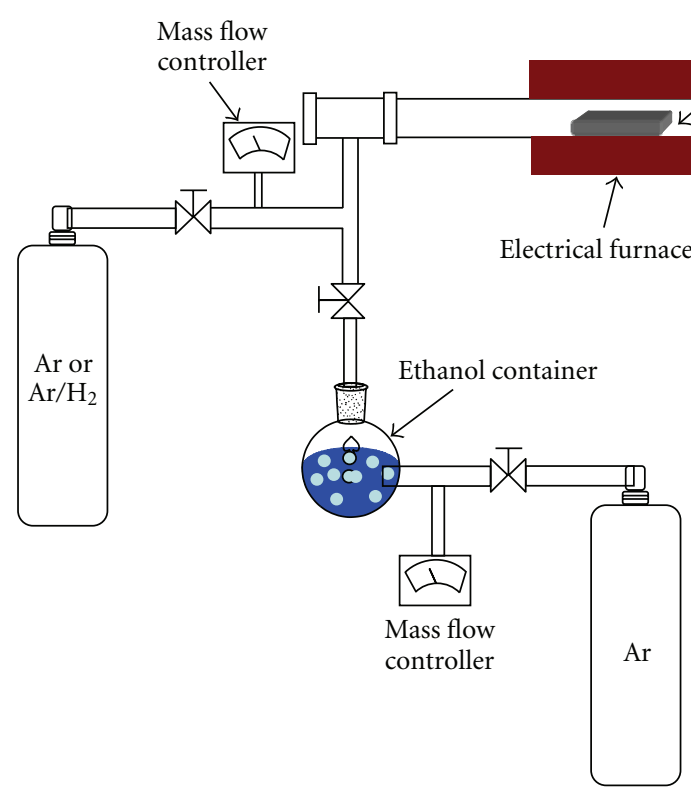

Figure 1: Diagram of the CCVD system used in this study.

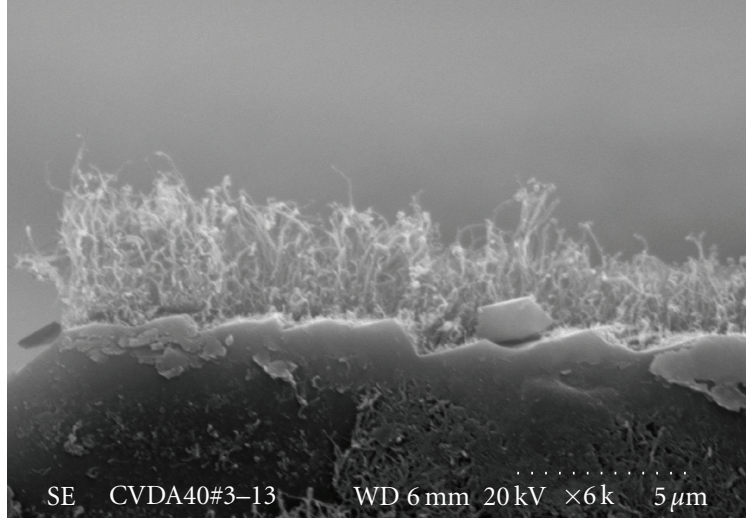

FIgURE 2: Cross-sectional FESEM image of as-grown SWCNTs.

association of a constant number of them (ca. 20). Similar results were observed by E. Einarsson et al. [36] during the synthesis of carbon nanotubes on quartz substrates under vacuum conditions. In that study, bundles were formed by no more than 10 SWCNTs adhered along the whole length of the nanotube. This association is expected to be due to the presence of a carbon coating, as confirmed by the HRTEM micrographs shown in Figure 3(a). This amorphous carbon can be easily removed by a mild sonication treatment in a mixture of ethanol-isopropyl alcohol $(4: 1)$. Figure 3(b) shows the SWCNTs released from the former bundles after sonication.
The presence of impurities in the as-synthesized materials (i.e., amorphous carbon) was also studied by thermogravimetry, TGA. Figure 4 shows the thermogravimetric profile of the as-synthesized SWCNTs. The weight loss is very low in a wide range of temperatures ( 373 to $1023 \mathrm{~K}$ ) indicating that a very low amount of amorphous carbon is present, as observed by HRTEM.

Dimensions of the as-synthesized SWCNTs were also evaluated from the nitrogen adsorption isotherms BET at $77 \mathrm{~K}$. The representative adsorption isotherm, which is the average of two experimental isotherms, is shown in Figure 5. In order to apply to real adsorption data the BET isotherm equation, it is habitual to use the BET equation in linear form in the region $0.05<x<0.4$ of the isotherm, where $x=P / P_{0}$ is the relation between the adsorption equilibrium pressure, $P$, and the adsorbate vapor pressure, $P_{0}$ [29]. The specific surface area was calculated by means of the linear BET plot, which made possible the computation of the BET surface area, that is, $\mathrm{S}^{\mathrm{BET}}$ (see Table 1) $[26,27,29]$.

Adsorption in the micropores is the main method applied for the measurement of the microporous volume, by means of the Dubinin linear plot, the t-plot method $[27,29,30]$ and, the linear plot of the Langmuir- type isotherm for volume filling $[29,31]$. In the present case the Dubinin and Langmuir type linear plots to adsorption data taken from the isotherm in the range $0.001<x<0.1$ were applied. Thereafter, the Gurvich rule was applied for the calculation of the Dubinin micropore volume $W_{\mathrm{MP}}^{\text {Dubinin }}$ $[29,30]$ and the Langmuir- type equation micropore volume $W_{\mathrm{MP}}^{\mathrm{LT}}($ see Table 1$)$. 


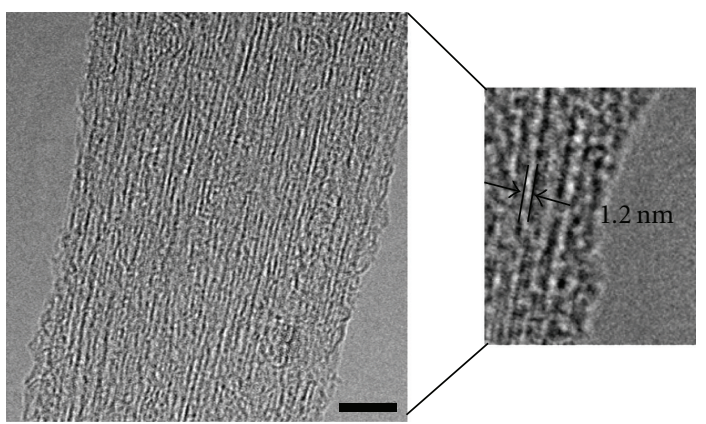

(a)

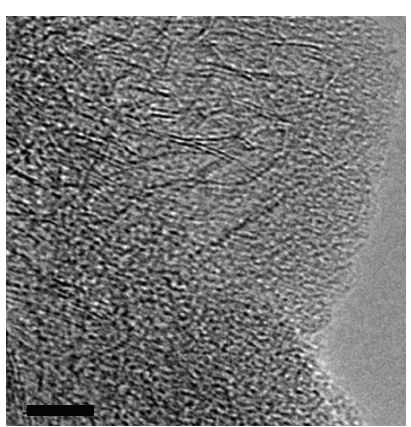

(b)

FIgURE 3: High-resolution TEM images of "as-synthesized" SWCNTs packets grown on Co/Mo-quartz substrates (a) and SWCNTs after a soft treatment of sonication in an alcohol mixture (b). Bar : $5 \mathrm{~nm}$.

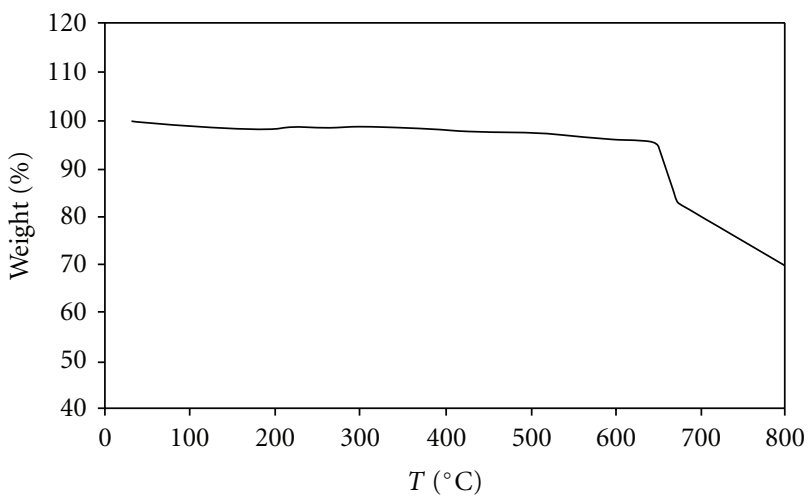

FIGURE 4: Thermogravimetric profile of the as-synthesized SWCNTs.

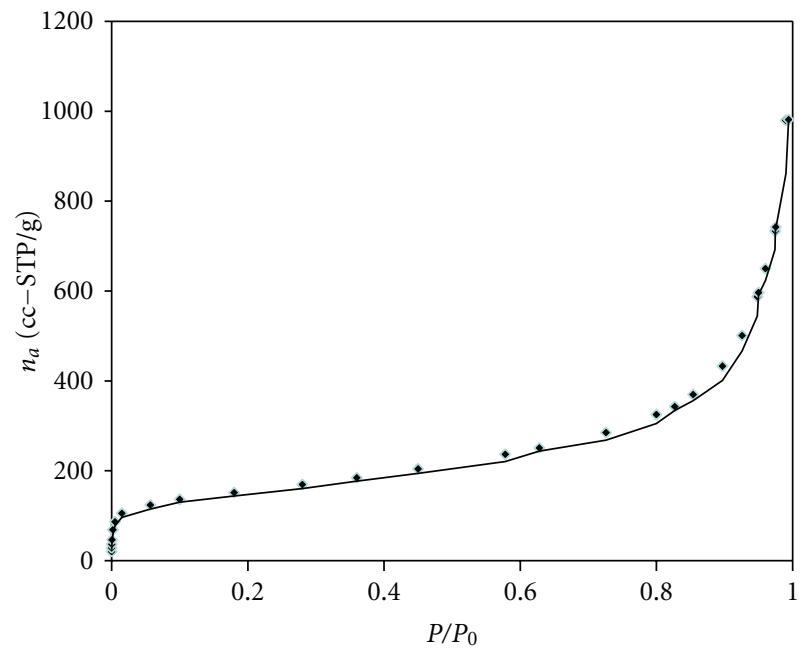

FIgURE 5: Adsorption isotherm of nitrogen at $77 \mathrm{~K}$ on the synthesized SWCNTs.

The Saito-Foley pore size distribution (SF-PSD) of the synthesized SWCNTs is shown in Figure 6. The mode of the SF-PSD distribution is reported in Table 1.

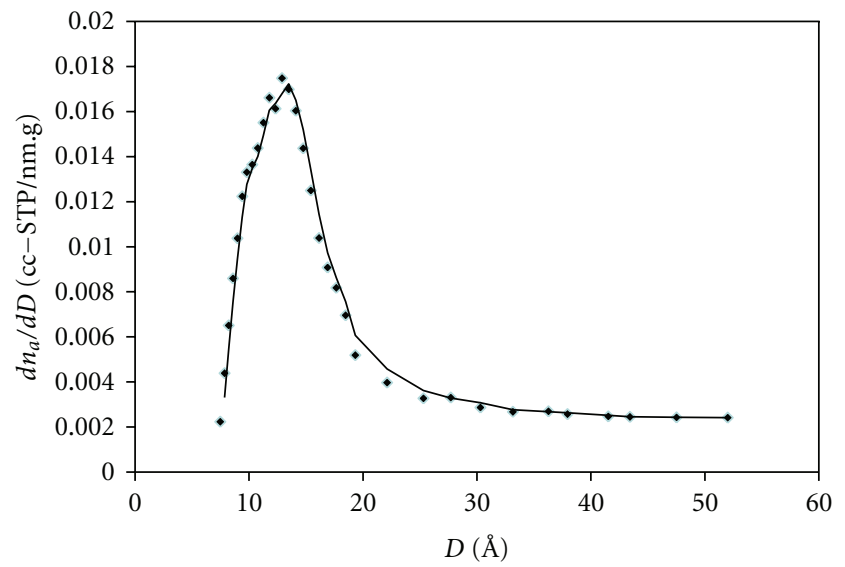

Figure 6: Saito-Foley pore size distribution.

The pore size distribution of the synthesized SWCNTs, corresponding to the Non local Density Functional Theory, is shown in Figure 7. The mode of the DFT-PSD distribution is reported in Table 1 .

The adsorption data displayed in Table 1 demonstrates that the analiyzed SWCNTs exhibit a relatively large specific surface area. In addition, the calculated micropore volume was $W_{\mathrm{MP}} \approx 0.21 \mathrm{~cm}^{3} / \mathrm{g}$. Besides, the calculated pore size distributions indicate that the synthesized SWCNTs have a slightly heterogeneous distribution of pores with a clear, and highly populated, maximum at $c a .1 .35 \mathrm{~nm}$. The above results unambiguously show the absence of mesoporosity in the sample.

Consequently, the adsorption data indicates that the adsorption of the obtained SWCNTs is completely restricted to the micropore region, exhibiting a relatively high micropore volume.

Raman measurements reported here were performed by using the $785 \mathrm{~nm}$ diode laser, as the corresponding spectra recorded with 633 and $514 \mathrm{~nm}$ showed very poor spectra in the Raman shift region below $300 \mathrm{~cm}^{-1}$ where Radial Breathing Modes (RBMs) of SWCNTs appear. This indicates that the CNTs grown by the method here reported are resonantly excited by the $1.58 \mathrm{eV}(785 \mathrm{~nm})$ laser. Figure 8(a) 


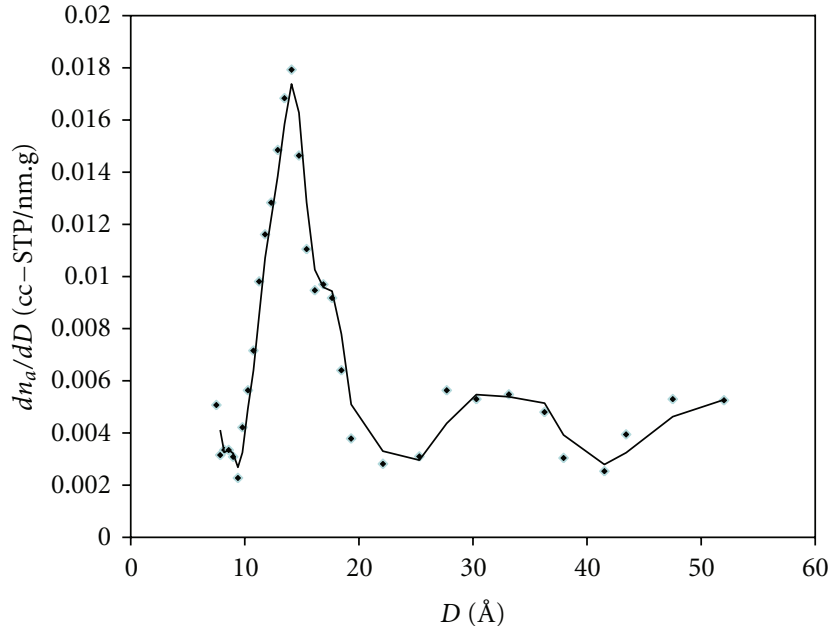

Figure 7: Pore size distribution of the synthesized SWCNTs by using the Non local density functional theory.

shows the Raman spectrum from the "as-synthesized" SWCNTs grown on Si. Typical bands of Raman spectra of SWCNTs excited by the $1.58 \mathrm{eV}(785 \mathrm{~nm})$ laser (G-band at $1594 \mathrm{~cm}^{-1}$, D-band at $1296 \mathrm{~cm}^{-1}, \mathrm{G}^{\prime}$-band at $2580 \mathrm{~cm}^{-1}$, and RBM modes in the low Raman shift region) are marked. The high intensity ratio G/D unambiguously indicates the high purity of SWCNTs. The Raman shift of the different RBMs can be correlated with the diameter of the SWCNT, by using an empirical formula [37], $d=248 / \nu_{\mathrm{RBM}}$, where " $\nu_{\mathrm{RBM}}$ " is the corresponding wavenumber $\left(\mathrm{cm}^{-1}\right)$ and " $d$ " is the diameter of the SWCNT (nm). The diameter determined by this approximation shows a narrow distribution ranging from 0.9 to $1.2 \mathrm{~nm}$ that agrees with the dimensions measured by HRTEM and nitrogen adsorption. On the other hand, the resonance observed in the RBM region can be correlated with the presence of small bundles formed by an apparently constant number of SWCNTs, as observed by HRTEM. In such a way, the contact among SWCNTs could be responsible for the attenuation of the Raman breathing modes and so for the resonance observed in the RBM region.

Figures 8(b) and 8(c) show the Raman spectra of SWCNTs grown on quartz and $\mathrm{SiO}_{2} / \mathrm{Si}$, respectively, but after a dispersion treatment and posterior deposition on Si $(8(b))$ and glass (Figure $8(\mathrm{c})$ ) surfaces. The variations observed in the RBM region with respect to the "as-synthesized" can be attributed to the different degree of aggregation of the SWCNTs. In particular, it has been reported that the intensity of the band centered around $269 \mathrm{~cm}^{-1}$ can be used to probe nanotube aggregation. The fact is that this characteristic band is almost absent for dispersed SWCNTs and increases, in relation to those appearing at lower frequency values, when the aggregation level increases [38]. In the inset of Figure 8 it is clearly shown how the intensity of such a band decreases drastically in the case of dispersed nanotubes. The profile of the RBM region is similar in (b) and (c), indicating similar population distribution of diameters in the dispersed

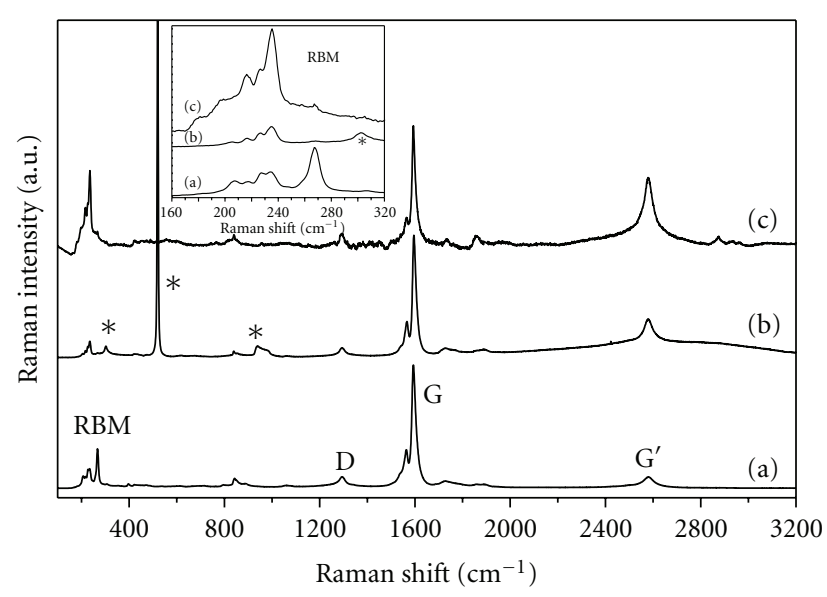

Figure 8: Raman spectra of as-synthesized SWCNTs (a) and of the dispersed SWCNTs deposited on Si (b) and glass (c) surfaces. ${ }^{*} \mathrm{Si}$ bands. Broad Raman bands of glass have been subtracted. The inset corresponds to a magnification of the RBM region. All the spectra are normalized to the G-band height. Laser excitation at $785 \mathrm{~nm}$.

CNTs. Nevertheless, the whole RBM region in the case of CNTs deposited on glass is more intense than when deposited on Si, for an equal G-band intensity of both spectra. Due to the singular "resonant" origin of the RBM modes (optical transitions of the SWCNTs with the energy of the excitation laser), the large global intensity of the RBM region in the (c) case could be attributed either to better "resonance" conditions in this last case or to a larger amount of CNTs present in the laser spot.

\section{Conclusions}

Vertically aligned single-wall carbon nanotubes have been obtained by using alcohol chemical vapor deposition process. Simplification of ACCVD setup experimental conditions is of interest toward a low-cost, up-scalable synthesis of high-quality SWCNTs. Surprisingly these nanotubes are organized in narrow and homogeneous bundles of $c a .30 \mathrm{~nm}$ diameter that are formed by association of no more than 20 SWCNTs. This association of nanotubes has been evidenced by HRTEM and Raman spectroscopy and represents a new CNT material opening up new perspectives in the field of nanoelectronics and optics.

\section{Acknowledgments}

The authors gratefully recognize the financial support provided by MEC through Grants MAT2006-08158, MAT200766476-C02-02, and European Community FP6-029192. Financial support from US Department of Energy through the Massey Chair Project at University of Turabo is also acknowledged. The "Servicio Interdepartamental de Investigación (SIdI)" from Universidad Autónoma de Madrid and "Centro de Microscopia Luis Bru" from Universidad Complutense de Madrid are acknowledged for the use of the HRTEM and FESEM facilities. 


\section{References}

[1] S. Iijima, "Helical microtubules of graphitic carbon," Nature, vol. 354, no. 6348, pp. 56-58, 1991.

[2] S. Iijima and T. Ichihashi, "Single-shell carbon nanotubes of 1nm diameter," Nature, vol. 363, no. 6430, pp. 603-605, 1993.

[3] P. Calvert, "A recipe for strength," Nature, vol. 399, no. 6733, pp. 210-211, 1999.

[4] J. I. Pascual, J. Méndez, J. Gómez-Herrero et al., "Properties of metallic nanowires: from conductance quantization to localization," Science, vol. 267, no. 5205, pp. 1793-1795, 1995.

[5] P. G. Collins, A. Zettl, H. Bando, A. Thess, and R. E. Smalley, "Nanotube nanodevice," Science, vol. 278, no. 5335, pp. 100103, 1997.

[6] M. S. Dresselhaus, G. Dresselhaus, and P. Avouris, Eds., Carbon Nanotubes: Synthesis, Properties and Application, Springer, Berlin, Germany, 2001.

[7] S. Talapatra, S. Kar, S. K. Pal et al., "Direct growth of aligned carbon nanotubes on bulk metals," Nature Nanotechnology, vol. 1, no. 2, pp. 112-116, 2006.

[8] S. I. Cha, K. T. Kim, S. N. Arshad, C. B. Mo, K. H. Lee, and S. H. Hong, "Field-emission behavior of a carbon-nanotubeimplanted Co nanocomposite fabricated from pearl-necklacestructured carbon nanotube/Co powders," Advanced Materials, vol. 18, no. 5, pp. 553-558, 2006.

[9] E. Minoux, O. Greening, K. B. K. Teo et al., "Achieving highcurrent carbon nanotube emitters," Nano Letters, vol. 5, no. 11, pp. 2135-2138, 2005.

[10] Z. Li, H. R. Kandel, E. Dervishi et al., "Does the wall number of carbon nanotubes matter as conductive transparent material?" Applied Physics Letters, vol. 91, no. 5, Article ID 053115, 3 pages, 2007.

[11] D. N. Futaba, K. Hata, T. Yamada et al., "Shape-engineerable and highly densely packed single-walled carbon nanotubes and their application as super-capacitor electrodes," Nature Materials, vol. 5, no. 12, pp. 987-994, 2006.

[12] R. Saito, G. Dresselhaus, and M. S. Dresselhaus, Eds., Physical Properties of Carbon Nanotubes, Imperial College Press, London, UK, 1998.

[13] V. Lordi, N. Yao, and J. Wei, "Method for supporting platinum on single-walled carbon nanotubes for a selective hydrogenation catalyst," Chemistry of Materials, vol. 13, no. 3, pp. 733-737, 2001.

[14] M. Yu, H. H. Funke, J. L. Falconer, and R. D. Noble, "High density, vertically-aligned carbon nanotube membranes," Nano Letters, vol. 9, no. 1, pp. 225-229, 2009.

[15] B. J. Hinds, N. Chopra, T. Rantell, R. Andrews, V. Gavalas, and L. G. Bachas, "Aligned multiwalled carbon nanotube membranes," Science, vol. 303, no. 5654, pp. 62-65, 2004.

[16] S. Kim, J. R. Jinschek, H. Chen, D. S. Sholl, and E. Marand, "Scalable fabrication of carbon nanotube/polymer nanocomposite membranes for high flux gas transport," Nano Letters, vol. 7, no. 9, pp. 2806-2811, 2007.

[17] E. Joselevich and C. M. Lieber, "Vectorial Growth of Metallic and Semiconducting Single-Wall Carbon Nanotubes," Nano Letters, vol. 2, no. 10, pp. 1137-1141, 2002.

[18] J. E. Fischer, W. Zhou, J. Vavro et al., "Magnetically aligned single wall carbon nanotube films: preferred orientation and anisotropic transport properties," Journal of Applied Physics, vol. 93, no. 4, pp. 2157-2163, 2003.

[19] S. C. Youn, D.-H. Jung, Y. K. Ko, Y. W. Jin, J. M. Kim, and H.-T. Jung, "Vertical alignment of carbon nanotubes using the magneto-evaporation method," Journal of the American Chemical Society, vol. 131, no. 2, pp. 742-748, 2009.
[20] K. Hata, D. N. Futaba, K. Mizuno, T. Namai, M. Yumura, and S. Iijima, "Water-assisted highly efficient synthesis of impurity-free single-walled carbon nanotubes," Science, vol. 306, no. 5700, pp. 1362-1364, 2004.

[21] T. Yamada, T. Namai, K. Hata et al., "Size-selective growth of double-walled carbon nanotube forests from engineered iron catalysts," Nature Nanotechnology, vol. 1, no. 2, pp. 131-136, 2006.

[22] C. Wang, H. T. Chen, S. C. Chang, S. Y. Cheng, and T. S. Chin, "Strong carbon-nanotube-polymer bonding by microwave irradiation," Advanced Functional Materials, vol. 17, no. 12, pp. 1979-1983, 2007.

[23] S. Maruyama, R. Kojima, Y. Miyauchi, S. Chiashi, and M. Kohno, "Low-temperature synthesis of high-purity singlewalled carbon nanotubes from alcohol," Chemical Physics Letters, vol. 360, no. 3-4, pp. 229-234, 2002.

[24] Y. Murakami, Y. Miyauchi, S. Chiashi, and S. Maruyama, "Characterization of single-walled carbon nanotubes catalytically synthesized from alcohol," Chemical Physics Letters, vol. 374, no. 1-2, pp. 53-58, 2003.

[25] Y. Murakami, Y. Miyauchi, S. Chiashi, and S. Maruyama, "Direct synthesis of high-quality single-walled carbon nanotubes on silicon and quartz substrates," Chemical Physics Letters, vol. 377, no. 1-2, pp. 49-54, 2003.

[26] S. J. Gregg and K. S. W. Sing, Adsorption Surface Area and Porosity, Academic Press, London, UK, 1982.

[27] F. Rouquerol, J. Rouquerol, and K. Sing, Adsorption by Powder Porous Solids, Academic Press, New York, NY, USA, 1999.

[28] M. Thommes, "Physical adsorption characterization of ordered and amorphous mesoporous materials," in Nanoporous Materials: Science and Engineering, G. Q. Lu and X.S. Zhao, Eds., chapetr 11, p. 317, Imperial College Press, London, UK, 2004.

[29] R. Roque-Malherbe, Adsorption and Diffusion in Nanoporous Materials, CRC Press, Boca Raton, Fla, USA, 2007.

[30] M. M. Dubinin, "Physical adsorption of gases and vapors in micropores," Progress in surface and membrane science, vol. 9, pp. 1-70, 1975.

[31] R. Roque-Malherbe, "Complementary approach to the volume filling theory of adsorption in zeolites," Microporous and Mesoporous Materials, vol. 41, no. 1-3, pp. 227-240, 2000.

[32] G. Horvath and K. Kawazoe, "Method for the calculation of effective pore size distribution in molecular sieve carbon," Journal of Chemical Engineering of Japan, vol. 16, no. 6, pp. 470-475, 1983.

[33] A. Saito and H. C. Foley, "Curvature and parametric sensitivity in models for adsorption in micropores," AIChE Journal, vol. 37, no. 3, pp. 429-436, 1991.

[34] R. Roque-Malherbe, Physical Chemistry of Materials, CRC Press, Boca Raton, Fla, USA, 2009.

[35] A. V. Neimark and P. I. Ravikovitch, "Capillary condensation in MMS and pore structure characterization," Microporous and Mesoporous Materials, vol. 44-45, pp. 697-707, 2001.

[36] E. Einarsson, H. Shiozawa, C. Kramberger et al., "Revealing the small-bundle internal structure of vertically aligned singlewalled carbon nanotube films," Journal of Physical Chemistry C, vol. 111, no. 48, pp. 17861-17864, 2007.

[37] A. Jorio, R. Saito, J. H. Hafner et al., "Structural (n, m) determination of isolated single-wall carbon nanotubes by resonant Raman scattering," Physical Review Letters, vol. 86, no. 6, pp. 1118-1121, 2001. 
[38] D. A. Heller, P. W. Barone, J. P. Swanson, R. M. Mayrhofer, and M. S. Strano, "Using Raman spectroscopy to elucidate the aggregation state of single-walled carbon nanotubes," Journal of Physical Chemistry B, vol. 108, no. 22, pp. 6905-6909, 2004. 

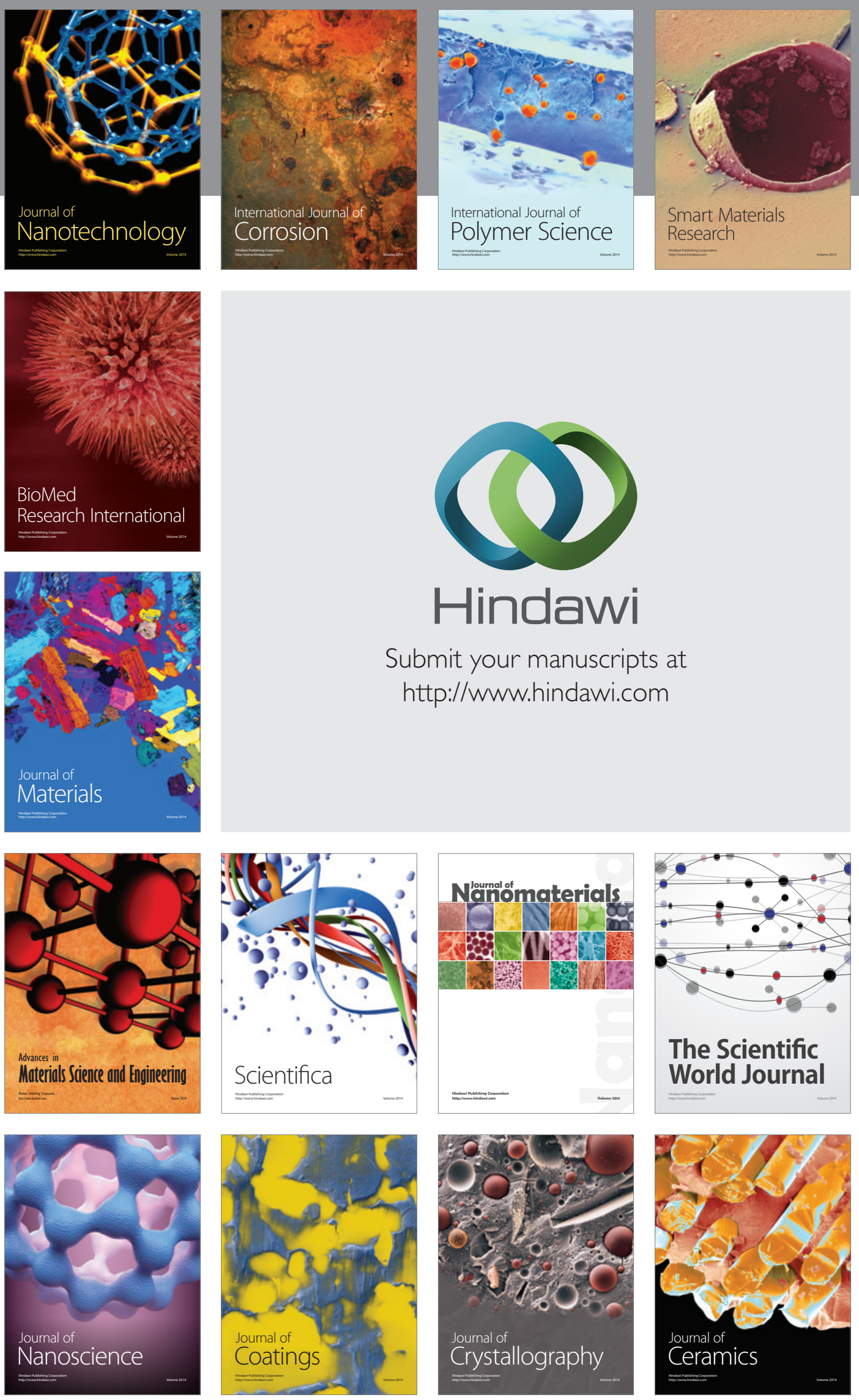

The Scientific World Journal

Submit your manuscripts at

http://www.hindawi.com

\section{World Journal}

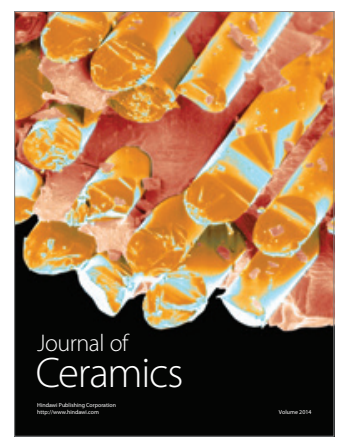

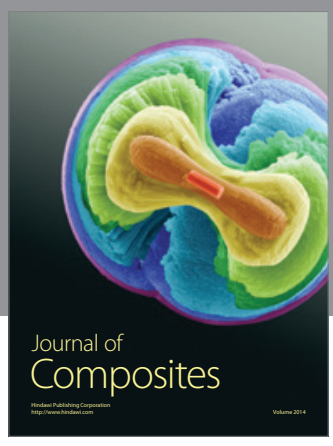
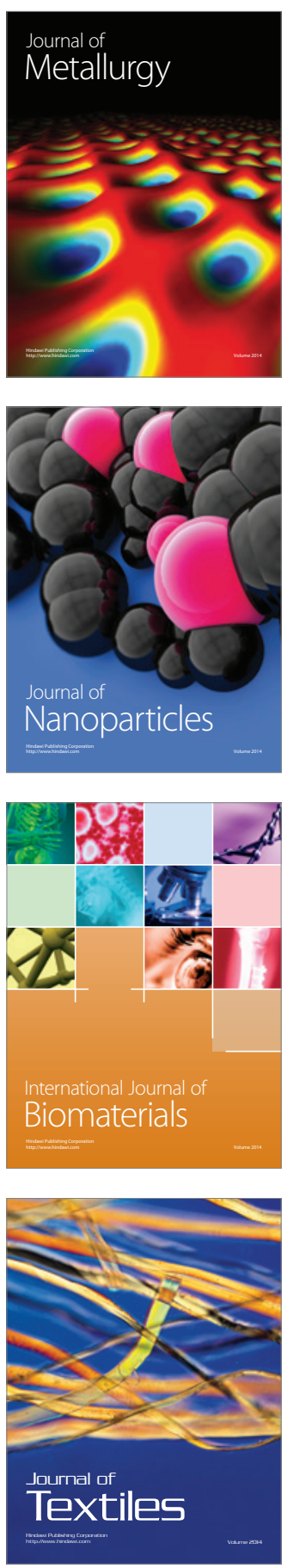